\title{
STÉPHANE HUCHET
}

[I]

Partilhas no ambiente da crítica

\section{RESUMO}

Procede-se, neste artigo, a uma análise, em suas dimensões conceitual e histórico-prática, do conceito de crítica desdobrado em três tipos: crítica de legitimação, de empatia e de intervenção. São considerados, ainda, o papel do artista contemporâneo como crítico, as especificidades da linguagem crítica e os ajustes de categorias de julgamento exigidos pela arte contemporânea.

PALAVRAS-CHAVE

Crítica de arte; Arte contemporânea; Linguagem crítica. 
Jacques Leenhardt situa bem a integração final dos dois níveis críticos, de legitimação e de empatia quando fala de "reformulação sensível da arte na linguagem", de um texto que "funciona, por sua vez, como uma escola do ver, uma pedagogia da sensibilidade". LEENHARDT, 2000, p. 20.

\section{PARTILHAS NO AMBIENTE DA CRÍTICA}

Falar da "crítica" nos coloca frente a uma dupla dimensão: conceitual e prática. Este par conceitual/prática já divide a categoria de "crítica" e pode ser desdobrado em rede. O conceito de "crítica" é conceito - para sê-lo, deve ser delineado especulativamente - e história, porque o conceito evoluiu e mudou com o tempo. $O$ conceito de "crítica" como dimensão histórica já leva, portanto, para o lado do outro pólo do par, a prática. A prática da "crítica" é histórica. Sua história pode ser feita. Ao mesmo tempo, a prática histórica da "crítica" preenche de certa maneira o conceito que se tem (que se teve e que se tinha) da "crítica" em certas épocas, o que leva a prática de volta para o lado do primeiro pólo do par, o conceitual.

A prática da "crítica" pode ter várias modalidades: intervenção, empatia, legitimação, com suas dimensões próprias e interligadas.

A crítica de legitimação consiste em aproximar o aproximável ou o não-aproximável do público, em criar uma relação diplomática com ele, em propor as chaves de entrada para que possamos entender e garantir uma mínima identificação dos componentes semiológicos e semânticos de uma obra ou de um dispositivo artístico. Representa o nível de base da crítica. Agora, essa dimensão "legítima” da crítica de legitimação pode ver seu teor e seu raio de abrangência restringidos se insistir em tornar o produto ou o artefato analisado demasiadamente frequentável, inteletualmente reduzido a sua mera dimensão "coisal”: arrisca achatá-lo na criação de uma relação exageradamente proporcional à capacidade "normal" de recepção. É obra domesticada. Sabemos que certas críticas de arte não passam de descrições que se atêm ao "fazer" para melhor evitar a interpretação e a proposta de um juízo fundamentado. Assim, a obra deve imperativamente, por x motivos, existir, passar, ser aceita pelo público.

Assim, existem dois aspectos da crítica de legitimação: o positivo, que destrincha e aproxima a complexidade de um nível desejável de entendimento,' encontra melhor forma de se manifestar quando condiciona e sustenta o jogo da crítica de empatia e de intervenção; o aspecto "negativo" pode ter finalidades declaradamente cínicas através do desvirtuamento e da eventual cooptação do trabalho analítico no uso econômico do simbólico. É a propósito do perigo generalizado de uma tal cooptação institucional da arte pelo Capital, de uma "produção cultural considerada como marketing, como estratégia de venda de um certo tipo de visibilidade ou como supermercado de lazer" 
que, nas "anotações intempestivas" de seu livro o + é deserto, Hélio Fervenza lamenta a falta, na crítica hodierna, de "um pensamento não-instrumentalizado, nem capitalizado pelos organismos hegemônicos, conjuntamente com uma ação propondo realmente outras formas de produção e a efetiva autonomia do espaço artístico." Já em 1975, na revista Malasartes, Ronaldo Brito escrevia que os textos críticos "funcionam como esotéricos apoios publicitários às obras [...] Estão ali para superpor mais um nível ao discurso que vai envolver o produto e torná-lo, num primeiro momento, objeto cultural e em seguida objeto de prazer e consumo."3 Denunciava a "equação comercial" envolvendo obra, instituição e texto.

Toda boa crítica deve fazer convergir várias virtudes epistemológicas, notadamente uma consciência de seu papel de antecipação histórica. Lembremos os vínculos integrados da história com a crítica. A história integrará a seu material de análise de uma época o que a época disse sobre as produções artísticas que surgiram nela. Cabe à crítica realizar o trabalho de observação, de levantamento, de seleção e de análise da produção contemporânea. A crítica arrisca a produção de juízos sobre as obras analisadas. Ela lega às gerações vindouras um material que, de crítico quando escrito, se tornará histórico quando futuros historiadores estudarem a época em questão.

Quando Icleia Cattani escreve que "o pesquisador sobre arte contemporânea deverá ter uma formação teórica, simultaneamente ampla e aprofundada, conjugando história da arte, teoria e crítica de arte, além de conhecimento em outras áreas: sociologia, filosofia, história da cultura, semiologia e semiótica", ${ }^{4}$ ela ressitua a crítica dentro de um amplo campo de forças epistemológicas no qual nota elos singulares. Valeria relembrar, como já fizemos, ${ }^{5}$ todos os instrumentos metodológicos próprios às "ciências" que perante a "arte" como conceito abrangente e genérico que reúne num mesmo universo simbólico certas categorias de imagens, objetos e produções estéticas, constituem tantas maneiras de estruturar uma aproximação singular da(s) "arte"(s). ${ }^{6}$

A crítica de empatia é uma clareira dentro da crítica legitimadora. A ela associamos maneiras de desposar o objeto analisado, de seguir suas linhas de força através de uma motivação que supera o nível de explicação e de distribuição dos elementos necessários ao entendimento mínimo de uma obra ou de um dispositivo artístico pelo público, para entrar na dinâmica crítica propriamente dita. Usamos o termo "empatia" propositadamente, sabendo do teor anacrônico do termo no contexto contemporâneo, mas ele se aproxima daquilo que Walter Benjamin chamou de teor de verdade, para mostrar como supera o teor coisal, característico do primeiro nível analisado acima, o da simples legitimação. Corresponde ao ajuntamento das condições enunciativas para, do e no espaço diferencial da obra ou do dispositivo, ressaltar um sentido que essa obra institui e/ou ritualiza. Trata-se, na verdade, da projeção da imagem crítica, deflagração simbólica e semântica se depreendendo dos interstícios do dispositivo ou da obra, e para os quais é preciso um tipo de olhar singular. A crítica empática não "traduz" a obra

FERVENZA, 2003, p. 80.

BRIT0, 2006a, p. 56-57. Inúmeros pontos desse texto politicamente incisivo adquiriram uma nova pertinência hoje, no contexto do "mercado da exposição" ao qual Hélio Fervenza faz alusão.

CATTANI, 2004a, p. 148.

Ver a palestra que fizemos em 2002 no XXII ${ }^{\circ}$ Colóquio Brasileiro de História da Arte (HUCHET, 2002).

Ver: DUVE, 1989. 
em palavras diplomáticas, mas segue suas linhas de injunção e se entrega a seu jogo para melhor ressaltar suas linhas de fuga. Apresenta os condicionantes da passagem do sentido. Desposando o que analisa - em vez de traçar, como na primeira, cortes e recortes "coisais" para viabilizar uma obra que precisa receber de fora uma legitimidade que não alcançaria por si mesma -, a crítica empática - como filologia do corpo - duplica ou redobra o toque da obra. Trata-se, em última instância, de uma erótica crítica que está numa verdadeira relação de troca com o toque de uma obra. Não existe combate com o sentido, mas uma livre convergência de texturas e de plasticidades artísticas e especulativas.

A terceira "crítica" é a de intervenção. A ela associamos a ideia de crítica militante, engajada, polêmica, combatente. No entanto, ela não se separa das precedentes práticas críticas, porque é impossível levar para frente uma crítica de intervenção sem ter entendido nas suas entranhas as implicações mais consequentes de um trabalho artístico. Dentro dessa categoria, as críticas de arte realizadas por Aracy Amaral no calor das exposições de arte contemporânea desde os anos 1960 representam um material de grande relevância, dinâmico, instigante, fragmentos juntados passo a passo graças a uma perseverança admirável. Trata-se de um mapeamento da produção ao vivo de uma época, prometido a se tornar, como dissemos, um campo de estudo privilegiado para os historiadores da arte. Os textos de Ronaldo Brito, também, representam uma parte forte, no contexto brasileiro, da crítica de intervenção. Ao relê-los, nos sentimos em pleno terreno contemporâneo. Menos lembrada hoje, Sheila Leirner propunha nos anos 1970 críticas curtas, mas incisivas, que obedeciam a uma motivação combatente. A introdução da coletânea destes textos, intitulada Arte como medida, sintetiza bem o teor dessa crítica de intervenção:

a única maneira de ver a arte, portanto, é aquela ensinada pela própria arte. [...] A arte contemporânea trabalha com a paródia, ironia, metáfora, alusão; propõe a abertura da dúvida, da autocrítica, da contradição [...] Logo, a crítica que anda entrelaçada até à linguagem com essa profusão de novos valores tende a mostrar-se ambígua e escorregadia quanto a seu objeto de análise. Um pequeno parêntese: aí está também por que a crítica de hoje incompatibiliza-se cada vez mais com os conceitos de 'erro' ou 'injustiça', que usualmente querem Ihe impingir. Na verdade, a crítica atual deve eliminar de vez as definições abstratas universais, tais como 'qualidade', 'expressividade' [...] Estes resíduos dos velhos sistemas essenciais têm que ser urgentemente substituídos por análises concretas numa terminologia de ação, conflito, intenção e hipótese criativa. [...] O verdadeiro crítico é aquele que [...] vive da curiosidade, da indignação e da mais ampla prática da liberdade intelectual. ${ }^{7}$ 
Veremos mais tarde como outros críticos, artistas, apontarão o mesmo problema do ajuste entre arte e vocabulário crítico.

Na relação entre os três níveis de "crítica" que propomos, trata-se, no final das contas, de graus indissociáveis e integrados um no outro, a crítica empática sendo uma condição para a de intervenção, esta consistindo em projetar o pensamento analítico num círculo de implicações mais objetivadas, mais globais e afeitas a uma problematização socialmente mais voluntarista.

Refletindo sobre o desafio de uma "crítica" consistente existir hoje, Icleia Cattani pergunta se a crítica pode ainda "restabelecer seu papel fundamental de reflexão crítica, de criação de paradigmas, de determinação de parâmetros, de estruturação de um arcabouço conceitual, [...] definir os lugares da arte na sociedade, lugares a partir dos quais a própria arte possa ser realizada enquanto prática simbólica que abre para os 'mais-além' do real?"8

Nessa ordem de consideração, pensamos poder afirmar que o papel desempenhado na história por certos críticos engajados, entre, por exemplo, 1950 e 1990, exemplificam um tipo de atuação que condiz com essas tarefas. Sem entrar na questão do juízo de valor sobre tal ou tal crítico, pensamos em Clement Greenberg, Mário Pedrosa, Michael Fried, Frederico Morais, Ronaldo Brito, Pierre Restany, Aracy Amaral, Rosalind Krauss, Sheila Leirner, Germano Celant, Benjamin H. D. Buchloh, Douglas Crimp, Serge Daney etc. No entanto, já que a crítica de intervenção significa uma inserção clara num contexto sociocultural e político ao qual o discurso crítico é endereçado, integrando explicitamente a(s) obra(s) analisada(s) no crivo político que põe em perspectiva, deveríamos ampliar a questão da "crítica" de maneira clara a certos curadores, agentes e agenciadores institucionais que podem transformar as exposições que organizam em tantas posições críticas acerca da arte e do mundo em geral? Assim, acrescentaríamos à lista acima Harald Szeemann, Catherine David, por exemplo. Quem negaria que as exposições de Harald Szeemann desde 1969, de Catherine David desde os anos 1980 - L'époque, la mode, la morale, la passion (1987), Poetics/Politics, Documenta X (1997) -, são marcos históricos importantes da relação crítica, engajada, intervencionista e finalmente política com a arte contemporânea? Na época em que Szeemann organizava a famosa exposição Quando as Atitudes viram Formas, Bern, 1969, ou a Documenta 5, Kassel, 1972, ele introduzia nos seus breves textos de apresentação dimensões críticas primordiais. Eram exposições histórica e criticamente decisivas. Falando do observador que podia sentir dificuldade para se relacionar com as obras, Szeemann precisava que este se encontrava ao mesmo tempo "integrado" na dinâmica da exposição por ela juntar "as três formas magistrais da atividade de exposição: crítica - informação - documentação". ${ }^{9}$ No prefácio do catálogo da Documenta 5 , ele resumia sua teoria crítica da recepção e da exposição de uma maneira particularmente condizente com as prioridades da época:

CATTANI, 2004B, p. 65.

SZEEMANN, 1996, p. 28. 
a prestação do observador ou do visitante reside na diferenciação dos níveis de realidade na obra [...]. Seu conhecimento e sua análise ou discussão com a obra podem, por si só, [...] transformar as estruturas definidas da realidade na obra. Essa integração [...] do eventual e da interpretação pode ser empreendida e cumprida apenas pelos observadores, conquanto entendam a 'D5' e as obras propostas como representantes de todas as imagens do mundo. Assim, o equívoco que supõe que o conceito representa um método de valorização anartístico deveria ser eliminado. $O$ conceito é um metodo do 'ver' diferenciado, que tem como objetivo a eliminação do simples juízo 'sim-não'. ${ }^{10}$

Veremos daqui a pouco que Joseph Kosuth, no mesmo momento, apresentava a missão da arte conceitual como a de um método que não devesse mais nada ao juízo de valor baseado nos moldes tradicionais da crítica, mas que fosse intrinsecamente imanente. Nessa ordem de consideração, a frase de Szeemann tem consequências para a questão da partilha da "crítica": Szeemann sugere que a significação da obra contemporânea depende de uma situação relacional - já - na qual a responsabilidade e a criatividade semânticas são determinadas pelo jogo idiossincrático de uma individualidade receptiva singular que (re)constrói os vários níveis possíveis de realidade que lhe são propostos. De certa maneira, o "observador" sutiliza a especificidade tradicional do crítico - que detinha até agora a capacidade de lançar a obra no domínio da significação retro - e prospectiva -, graças a uma extensão e a uma ampliação dos mecanismos de "construção" semântica da obra. Trata-se de uma verdadeira partilha entre parceiros de uma situação, diferenciados, mas levados todos a agir para produzir-lhe o sentido...

$\mathrm{O}$ lema da partilha deve, antes de tudo, situar o artista num lugar privilegiado. Esse ponto é para nós de suprema importância. Não pensamos que o trabalho crítico deva e possa ainda ser distribuído entre capelas "profissionais". Manter a divisão entre "crítica" heterogênea e "crítica" imanente é absurdo e representa um reflexo corporativo retrógrado. Não é mais possível reduzir a produção crítica ao meio específico dos críticos profissionais. Aliás, o que significa "profissional"? O olhar do outro sobre o que o artista cria e expõe? Era o caso com a legitimação e a empatia. Mas a arte moderna e contemporânea nos mostra que a obra de arte é portadora de posições críticas em si e que a autoria do artista moderno e contemporâneo repousa sobre a capacidade de fazer de seu trabalho uma instância portadora, de dentro, de uma dimensão crítica que Ihe é inerente, intrínseca, a obra não sendo jamais uma casca dependendo do aporte externo de um profissional $x$ para consistir e insistir criticamente.

Já é fato histórico consumado que tantos textos ou escritos de artista trazem uma visão crítica sólida que dinamiza o trabalho analítico do observador, do crítico, do 
historiador. Até hoje, por exemplo, na questão da instalação, nunca encontramos melhor síntese da situação dessa prática artística na sua relação com seus antecedentes, o environment ou o ambiente, do que no balanço que Allan Kaprow fez em I99I quando reexpôs trabalhos de 1960-6I numa galeria de Paris. O diagnóstico crítico dele conseguiu condensar em poucas linhas um panorama histórico que nenhum crítico tinha ainda sintetizado com tanta pertinência. " Os escritos de Hélio Oiticica, também, na questão da expansão espacial da arte, do compartilhamento da plasticidade entre a arquitetura e os ambientes, são fontes de pensamento de primeira ordem com relação aos quais, em geral, o que é escrito a respeito vira repetição, paráfrase, longe de fazer jus à extrema complexidade da obra do artista. ${ }^{12}$ Os escritos de Robert Morris são também extraordinários exemplos de rigor, inteligência, cultura e consciência do porquê de sua trajetória. Com Robert Smithson ou Daniel Buren, ainda - a lista seria grande -, e mais recentemente, Jeff Wall, é de um verdadeiro festival de inteligência crítica que o leitor se beneficia. Os escritos de Jeff Wall, por exemplo, mostram o alto grau de consciência crítica que um artista pode alcançar quando tece sua própria obra artística com um conhecimento analítico muito aprofundado e criativo da história da arte. Nesses rápidos exemplos que mereceriam estudos sistemáticos, encontramos sempre artistas que fazem o leitor se beneficiar de sua alta capacidade de problematização crítica. Quando Jeff Wall diz que "ser crítico, para mim, é uma prática filosófica que não se contenta em separar o bem do mal, - isto é, a dar respostas e a emitir juízos -, mas que dramatiza as relações entre o que queremos e o que somos", ${ }^{3}$ o vemos ecoar de maneira mais possante o que Harald Szeemann formulava vinte anos antes, levando o debate na direção de uma consciência filosófica e política do artista sobre a dinâmica "mediadora" da própria imagem - sua dramaticidade. Em outra entrevista, falando do teor "político" da arte, cita Goya, Dostoiévski, Rodin, Proust, Munch, Grosz e Duchamp para dizer que todas as suas obras "têm um conteúdo político formulado enquanto problema filosófico e experiência de uma obra, de uma imagem, de uma história. [...] A certeza que flutua ao longo de uma curva de experiência em constante evolução é um modelo de reflexão e de atitude crítica". ${ }^{14}$

Essa consciência da arte como crítica exemplifica a capacidade de o artista contemporâneo ser, enquanto artista, um agenciador audacioso de questões críticas que ele produz e leva à existência. É um verdadeiro pesquisador. Podemos citar, por exemplo, as coletâneas organizadas por Ricardo Basbaum, Arte brasileira contemporânea: texturas, ficções, estratégias (Rio de Janeiro: Rios Ambiciosos, 200 I), por Maria Ivone dos Santos, Processos fotográficos na arte contemporânea (Porto Alegre: Editora da UFRGS, 2005), livros que respondem a projetos de séria e rica fundamentação e demonstram um conhecimento amplo dos desafios críticos da arte contemporânea. As "anotações intempestivas" que Hélio Fervenza faz em o + é deserto também participam de um espaço de problematização do estatuto da produção, da inserção, da apresentação e

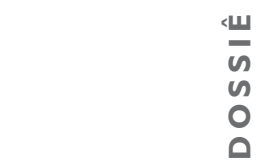

Citaçã̃o em HUCHET, 2006.

A nosso ver, a tese de Doutorado em Filosofia - sob orientação de Celso Favaretto (USP) - defendida em 2003 por Lisette Lagnado sobre "Hélio Oiticica: o mapa do Programa Ambiental" é uma pesquisa excelente que relança a perspectiva crítica sobre 0 artista de um modo inovador e inédito.

13 WALL, 200I, p. 180. 14 WALL, 200I, p. 239. 


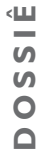

15

FERVENZA, 2003, p. 79-81.

Ver HUCHET, 2006b, p. 295-305. da circulação da arte, propondo como tarefa salutar sua desconstrução crítica. Quando pergunta se, no "mercado da exposição" que inunda a cultura de seus produtos, "o saber da arte e o saber sobre $a$ arte que os artistas desenvolvem não fica literalmente fora de jogo? [...] O que significa hoje em dia apresentar um trabalho?", ${ }^{15}$ Fervenza faz eco a problemáticas trabalhadas por críticos, teóricos e historiadores - por exemplo, Lisbeth Rebollo, Yves-Alain Bois e Jean-Marc Poinsot -, mas também e ainda mais por artistas que ele mesmo cita, como Marcel Broodthaers, Cildo Meireles, aos quais poderíamos acrescntar Daniel Buren e a geração conceitualista que investigou a questão do sistema da arte, etc. Assim, o artista que sabe comunicar e defender a consistência de sua prática artística, o sentido de suas estratégias de produção, de inserção, de exposição, de apresentação, de circulação ${ }^{16}$ etc., é, no campo ampliado da "crítica", seu mais importante agente.

Joseph Kosuth evocou a questão quando, no início de sua produção, pensava que era desejável que os críticos cedessem aos artistas a responsabilidade da crítica e, além disso, entendessem que, doravante, a crítica por excelência era a crítica imanente à obra. Em 1970, Kosuth justificava sua posição através da diferenciação entre percepção e concepção, a dualidade, o balanceamento entre ambas tendo sido o terreno frutífero da crítica de arte como intermediação entre percepção e conceito. Para ele, na definição da arte dita "conceitual”, interessada na investigação da natureza da arte, não se tratava de simples constructs perceptivos. Para Kosuth, estes representam o prato favorito da crítica que baseia seu material de análise na avaliação desses constructs, consolidando, assim, a diferença entre percepção e conceito. Esta diferença hipoteca a própria arte, por várias razões que não podemos aqui analisar, uma delas sendo a confirmação e a manutenção da confusão da arte e da estética. A arte, escreve Kosuth,

não é apenas a atividade de construção de proposições de arte mas um desenvolvimento, um aprofundamento de todas as implicações de todos os aspectos do conceito 'arte'. Por causa da dualidade implícita da percepção e da concepção na arte precedente, um intermediário (o crítico) pareceu útil. Essa arte [a arte conceitual, grifo nosso] de uma só vez anexa as funções da crítica e torna não necessário o intermediário. [N]o outro sistema: o público do crítico e do artista existia porque os elementos visuais da construção do 'como' davam à arte um aspecto de divertimento, propiciando-Ihe assim uma audiência. [...] A arte conceitual, portanto, é um inquérito feito por artistas que entendem que a atividade artística não é tão somente limitada à constituição de proposições de arte, mas, além, a investigação da função, da significação, do uso de todas e quaisquer proposições (de arte), e sua tomada em consideração dentro do 
conceito veiculado pelo termo geral 'arte'. Pela mesma razão, a dependência do artista com relação ao crítico de arte para pensar as implicações conceituais de suas proposições de arte e arguir suas explicações, ou é irresponsabilidade intelectual ou a mais ingênua espécie de misticismo. ${ }^{17}$
Tal visão, radical - mas, lembra Ronaldo Brito, na mesma época, em A Tradição do novo, Harold Rosenberg proclamava que o crítico de arte tinha-se tornado uma peça de museu $^{18}-$, gerou atritos inter profissionais, dos quais não saímos quando ainda encontramos críticos-críticos e artistas-artistas recusando a ideia de o artista ser também crítico ou curador. Em 1996, numa polêmica contra Yves-Alain Bois, Kosuth declarou inaceitável que uma história ou uma crítica de arte tendenciosa pudesse "colocar em perigo o que nós, artistas, avaliamos autêntico no processo artístico, aquilo que permite que assumamos a responsabilidade pessoal da significação que produzimos. É através desse ato de responsabilidade que os artistas se engajam com relação a um lugar cultural, uma história e uma comunidade social". ${ }^{19}$

Nos anos 1970, Harald Szeemann sublinhava também como o espaço institucional tinha dado ao "mediador" uma importância que superava de certa maneira o papel do próprio artista: "foi demonstrado que as instituições mais vivas são dirigidas por pessoas que pretendem que sua subjetividade se tornará, no final das contas, a coisa mais objetiva". ${ }^{20}$ Entretanto, Szeemann precisava que o interesse, deveras pequeno, do grande público para com a arte levou muitos colegas conservadores e curadores a se retirarem para "voltar-se para domínios onde a reflexão e a realização não eram confrontadas à incompreensão e ao equívoco inerentes à encenação das exposições de arte contemporânea”. ${ }^{21}$ No Brasil de hoje, existem exemplos de ação nessa mesma linha, mas para transformar o "retiro" em ponto nodal de invenção de estratégias de irradiação urbana suscetíveis de reiniciar um contato com o público. Muitos "coletivos" de artistas, desde muitos anos, mostram que a crítica de intervenção é praxe dentro do meio artístico, testemunhando por antecipação a veracidade da frase de Nicolas Bourriaud que diz: "a evolução da função das obras e de seu modo de apresentação testemunha uma urbanização crescente da experiência artística". ${ }^{22}$

A arte contemporânea põe a crítica frente a uma necessidade permanente de ajuste das categorias que ela usa e faz circular. $O$ desafio da recepção e da significação é de todas as épocas. Tem muito a ver com a invenção terminológica e conceitual. A definição de critérios de recepção e de análise da arte contemporânea depende de um certo estado do léxico crítico. Para analisar a arte contemporânea, dispomos das palavras sobredeterminadas da tradição, seja moderna, seja pré-moderna. Nos desfazemos dificilmente de seu apego. Constituem uma herança. É o que lembra Nicolas Bourriaud quando escreve:
17

KOSUTH, 199I, p. 39-40.

18 BRITO, 2006b, p. 29.

19 KosUTH, 1996, p. 174.

20 SZEEMANN, 1996a, p. 40-4l.

21 SZEEMANN, 1996a, p. 41.

22 BOURRIAUD, 200I, p. I5. 
AMARAL, 2006, p. 249.

KOSUTH, 1996, p. 173

BOURRIAUD, 200I, p. II5.

27

BOURRIAUD, 200I, p. II7.

BOURRIAUD, 200I, p. 86.

BOURRIAUD, 200I, p. 85. uma maioria esmagadora de críticos e filósofos repugnam a tomar a braços as práticas contemporâneas: elas ficam, portanto, essencialmente ilegíveis, já que não podemos perceber sua originalidade e sua pertinência analisando-as a partir de problemas resolvidos ou deixados suspensos pelas gerações precedentes. [...] Como decodificar essas produções atuais aparentemente inabarcáveis, sejam elas processuais ou comportamentais - em todo caso, 'estilhaçadas', conforme os padrões tradicionais - cessando de nos abrigar atrás da história da arte dos anos sessenta? ${ }^{23}$

Lema de todas as épocas. Em 1987, durante um simpósio da AICA na XIX Bienal de São Paulo, Aracy Amaral já fazia um diagnóstico parecido sobre a crítica de arte brasileira: "quer-nos parecer que a crítica não está tendo condições de acompanhar, no nível teórico, o deslanche da problemática da criatividade brasileira na área de artes visuais desde a década de 80", falando de um "desequilíbrio palpável, uma desproporção". ${ }^{24}$ Kosuth cerne o mesmo desafio: "assim que não se pode acrescentar novas palavras a um idioma (elas não seriam utilizáveis pela comunidade dos usuários dessa língua) se a língua em questão não está pronta a recebê-las, uma prática artística só pode ser considerada significativa se a etno-lógica cultural de uma sociedade acha convincente um certo tipo de jogo no seio do sistema significante da arte. 'Logicamente convincente', aqui, é o equivalente de 'culturalmente significante". ${ }^{25}$

Ainda é extremamente difícil encontrar a linguagem crítica para a(s) arte(s) quando elas escapam a um medium específico. Hoje, o "credo" modernista não vigora mais. Dentro de seus componentes formalistas, dizia que um medium encontra impacto crítico e histórico e repercussão disciplinar quando testa, analisa e submete à prova as convenções que herdou e lança mão de pistas inovadoras e de perspectivas linguagéticas dentro da especificidade deste medium. Precisamente, é importante notar que os dispositivos da "estética relacional" defendida por Nicolas Bourriaud não conseguem escapar à questão implícita e subterrânea de sua validade formal e estética. Quando, no "Glossário" de seu livro, ele diz que a prática artística consiste em “criar uma forma suscetível de 'durar', fazendo se encontrarem entidades heterogêneas num plano coerente, para produzir um relação com o mundo"; ${ }^{26}$ quando diz que a estética relacional é uma "teoria estética que consiste em julgar as obras de arte em função das relações interhumanas que elas figuram, produzem ou suscitam", ${ }^{27}$ já que o "glossário" não contém um item que se chamaria "juízo estético", Bourriaud acaba confessando que "o conteúdo dessas proposições artísticas deve ser julgado formalmente: em relação com a história da arte e levando em conta o valor político das formas". ${ }^{28}$ Essa "engenharia da intersubjetividade", ${ }^{29}$ portanto, não escapa à necessidade da produção de um mínimo de critérios formais para que se possa “julgá-la" segundo critérios de validade -"julgar", 
palavra estranha sob a mão de um crítico que matou em dez linhas a teoria da arte de Thierry de Duve, baseada no juízo estético. Bourriaud acrescenta: "seria absurdo julgar o conteúdo social ou político de uma obra 'relacional' livrando-se pura e simplesmente de seu valor estético". ${ }^{30}$

A questão do juízo de valor vigora de novo, irredutível. A questão de avaliar e argumentar se é arte boa ou não (etc.) fica inelutável. Neste sentido, Rainer Rochlitz tem razão quando precisa, após ter definido a crítica como "a fonte dos verdadeiros problemas estéticos: em particular das divergências que caracterizam o debate crítico", ${ }^{31}$ que cabe à estética filosófica melhorar o grau de formalização das questões que a crítica enuncia. Terreno arenoso: se, de um lado, todo mundo concorda em pensar que a crítica tem seu ponto de partida no objeto e na obra analisada, quais são seus revezamentos ou prolongamentos? "Em relação à crítica e à história da arte [...] a estética é uma teoria reflexiva" 32 que "busca dar conta da lógica das atitudes receptivas, críticas e historiadoras". ${ }^{33}$ A crítica é o "modelo básico da estética como teoria reconstrutiva da crítica". ${ }^{34}$ Esta última "reconstrói os procedimentos críticos e busca ver com clareza" ${ }^{35}$ Por outro lado, o elo forte entre a crítica e sua formalização filosófica pode gerar uma troca de posições dentro de uma economia intra especulativa. Diferencia-se, assim, da teoria de Gerd Bornheim que, de maneira neo-hegeliana, vê no surgimento da crítica a "morte da comunicação". Ressituando, mas sem fazer referência a ele, o momento específico da modernidade tal como Hegel, já o entendeu de maneira premonitória na sua Estética, Bornheim escreve, sintetizando a célebre tese hegeliana: "a vivência da arte topa como que de repente com uma experiência absolutamente nova em toda a história da arte - a ausência de fundamento. $O$ fundamento já não funciona mais como tal, perde vigência e deixa seus antigos sucedâneos - que são a configuração moderna de sujeito e objeto - como à deriva" ${ }^{36}$ Bornheim acrescenta: na arte anterior, "antes da comunicação entre sujeito e objeto, o todo do ambiente era comunicação", ${ }^{37}$ comunicação transparente, aquela entre palavras e coisas. O desaparecimento do fundamento gerou o desaparecimento da comunicação transparente entre seres e objetos, significados e significantes. Bornheim relaciona a perda da comunicação com o fosso existente entre arte e público, a crítica exercendo o papel de ponte "elucidatória" entre ambos. Interessante é o fato de a comunicação opaca entre arte e público precisar do prolongamento elucidatório para que a arte possa passar chegar ao receptor. A crítica "pressupõe justamente a crise daquela comunicação [...] a crítica vive da morte da comunicação". ${ }^{38}$ Bornheim sugere que esse fosso é a nova chance para que a arte encontre um novo espaço dinâmico de projeção. "Nada, entretanto, de pessimismo ou decadentismo nisso tudo: o fato é que a arte passa a desenvolver-se nos moldes de uma nova e outra vitalidade, com uma vontade de expansão realmente extraordinária". ${ }^{39}$

Pontes, passarelas, partilhas: a "crítica" colocada a nu por suas linhas de fuga, mesmo... Nos termos de Ricardo Basbaum, trata-se de realizar "conexões entre dois

30

BOURRIAUD, 200I, p. 86.

31 ROCHLITZ, 2003, p. 94.

32 ROCHLITZ, 2003, p. 96.

33 ROCHLITZ, 2003, p. 91.

34 ROCHLITZ, 2003, p. 94.

35 ROCHLITZ, 2003, p. 96.

36 BORNHEIM, 2000, p. 38-39.

37 BORNHEIM, 2000, p. 39.

38 BORNHEIM, 2000, p. 39.

39 BORNHEIM, 2000, p. 39. 
campos: um pensamento que saiba como arrancar da arte algo que o constitua e uma produção artística que se lança para fora de seus próprios limites em direção à intervenção cultural" ${ }^{40}$. Isso enuncia, a nosso ver, o programa de uma partilha produtiva no ambiente da "crítica".

\section{REFERÊNCIAS}

AMARAL, A. A. Situação da crítica no Brasil. In: Textos do Trópico do Capricórnio. Artigos e ensaios (1980-2005). V.I, Modernismo, arte moderna e o compromisso com o lugar. São Paulo: Ed. 34, 2006.

BASBAUM, R. Pensar com arte: o lado de fora da crítica. In: ZIELINSKY, M. (Org.). Fronteiras. Arte, crítica e outros ensaios. Porto Alegre: Editora da UFRGS, 2003.

BORNHEIM, G. As dimensões da crítica. In: MARTINS, M. H. (Org.). Rumos da crítica. São Paulo: Editora SENAC. Itaú cultural, 2000. p. 38-39.

BOURRIAUD, N. Esthétique relationnelle. Dijon: Les presses du réel, 2001.

BRITO, R. Análise do circuito. In: LIMA, S. (Org.). Experiência Crítica. São Paulo: Cosac\&Naify, $2006 a$. O acontecimento artístico. In: LIMA, S. (Org.). Experiência Crítica. São Paulo: Cosac\&Naify, $2006 b$.

CATTANI, I. Arte contemporânea: o lugar da pesquisa. In: FARIAS, A. (Org.). Icléia Cattani. Rio de Janeiro: FUNARTE, 2004a. (Coleção Pensamento Crítico)

CATTANI, Icléia. Questões atuais da crítica. Reflexões sobre a crítica, a arte 'à margem' e a poiética. In: FARIAS, Agnaldo (Org.). Icléia Cattani. Rio de Janeiro: FUNARTE, 2004b. (Coleção Pensamento Crítico)

DUVE, T. Au nom de l'art. Pour une archéologie de la modernité. Paris: Éditions de Minuit, 1989. (col. Critique)

FERVENZA, H. O + é deserto. São Paulo: Escrituras, 2003. (Col. Documento Areal 3)

HUCHET, S. A história da arte como multiplicidade. Anais do XXII CBHA. Cd rom. Porto Alegre: PUCRS, 2002.

A instalação em situação. In: NAZÁRIO, L.; FRANCA, P. (Orgs.). Concepções contemporâneas da arte. Belo Horizonte: Editora da UFMG, $2006 a$.

Rumos: continuidade(s) ou Big Bang simbólico? In: Rumos Artes Visuais 2005-2006. São Paulo: Itaú Cultural, 2006b. p.295-305.

KOSUTH, J. Art after Philosophy and After. Collected Writings, 1966-1990. Edited by Gabriele Guercio. Foreward by Jean-François Lyotard. Cambridge, Massachusetts, London, England: The MIT Press, I99I. p.39-40.

Les limites du regard. Voir et lire Ad Reinhardt. In: 69/96, avant-gardes et fin de siècle. 75 artistes

40

BASBAUM, 2003, p.I74. racontent leur parcours. Art Press Spécial. Hors-Série numéro 17, 1996.

LEENHARDT, J. Crítica de arte e cultura no mundo contemporâneo. In: MARTINS, M. H. (Org.). Rumos da 
crítica. São Paulo: Editora SENAC. Itaú cultural, 2000.

LEIRNER, S. Arte como medida. São Paulo: Perspectiva, 1982.

ROCHLITZ, R. Sobre as relações entre estética, crítica e história da arte. In: ZIELINSKY, M. (Org.).

Fronteiras. Arte, crítica e outros ensaios. Porto Alegre: Editora da UFRGS, 2003.

SZEEMANN, H. Le musée des obsessions. In: Écrire les expositions. Bruxelles: La lettre volée, 1996a. p. 40-4I.

Mythologies individuelles. In: Écrire les expositions. Bruxelles: La lettre volée, 1996b.

WALL, J. L'Académie intérieure. Entretien avec Jean-François Chevrier. In: CHEVRIER, Jean-François. Essais et entretiens. 1984-200I. Paris: École Nationale Supérieure des Beaux-Arts, 200 I.

\section{ГI

Doutor em Histoire et Théorie de l'Art, Ecole des Hautes Etudes en Sciences Sociales (1990), é Professor na Escola de Arquitetura da Universidade Federal de Minas Gerais e Pesquisador do CNPq. 